\title{
Action of Chicory Fructooligosaccharides on Biomimetic Membranes
}

\author{
A. F. Barbosa, ${ }^{1}$ R. S. Henrique, ${ }^{1}$ A. S. Lucho, ${ }^{2}$ V. Paffaro Jr., ${ }^{3}$ and J. M. Schneedorf ${ }^{1}$ \\ ${ }^{1}$ Biochemistry Laboratory, Federal University of Alfenas, R. Gabriel Monteiro da Silva, 700 Centro, 37130-000 Alfenas, MG, Brazil \\ ${ }^{2}$ Materials Group Lab, Chemistry Institute, Federal University of Alfenas, 37130-000 Alfenas, MG, Brazil \\ ${ }^{3}$ Integrative Animal Biology Laboratory, Institute of Biomedical Sciences, Federal University of Alfenas, 37130-000 Alfenas, MG, Brazil
}

Correspondence should be addressed to J. M. Schneedorf; zemasfs@gmail.com

Received 23 May 2014; Revised 17 October 2014; Accepted 19 October 2014; Published 16 November 2014

Academic Editor: Shen-Ming Chen

Copyright (C) 2014 A. F. Barbosa et al. This is an open access article distributed under the Creative Commons Attribution License, which permits unrestricted use, distribution, and reproduction in any medium, provided the original work is properly cited.

Fructooligosaccharides from chicory (FOSC) are functional prebiotic foods recognized to exert several well-being effects in human health and animal production, as decreasing blood lipids, modulating the gut immune system, enhancing mineral bioavailability, and inhibiting microbial growth, among others. Mechanisms of actions directly on cell metabolism and structure are however little known. In this sense this work was targeted to investigate the interaction of FOSC with biomimetic membranes (liposomes and supported bilayer membrane; s-BLM) through cyclic voltammetry, impedance spectroscopy, spectrofluorimetry, and microscopy. FOSC was able to disrupt the membrane structure of liposomes and s-BLM from the onset of molecular pores induced on it. The mechanism of interaction of fructans with biomimetic membranes suggests hydrogen bonding between the polyhydroxylated structure of the oligosaccharides and the negative polar group of L- $\alpha$-phosphatidylcholine (PC) present in both liposomes and s-BLM.

\section{Introduction}

As stated almost two decades ago, prebiotics are considered a nondigestible food ingredient that beneficially affects the host by selectively stimulating the growth and/or activity of one or a limited number of bacteria in the colon and thus improving host health [1]. A prebiotic group largely studied is the chicory fructooligosaccharides (FOSC). FOSC are fructans (carbohydrates with a great extent of fructosylfructose links) extracted on a commercial basis from the chicory root, namely, the Compositae family (Cichorium intybus) [2]. FOSC are also present in several fruits and vegetables species and are produced by transfructosylation of sucrose. These compounds comprise a functional food group containing mixed $\beta$-D-fructans with two to four $\beta(2$ 1) linked fructosyl units displaying a terminal $\alpha$-D-glucose residue, as kestose, nystose, fructosylnystose, and fructofuranosylnystose, among others [3]. FOSC differs from inulin, a well-known fructan of a high degree of polymerization (DP), as well as oligofructose, a small FOS (DP about 5) produced during endoglycolitic hydrolysis of inulin. FOSC are considered to arrive the human gastrointestinal tract almost without hydrolysis, being a carbon source for short-chain fatty acids by bifidobacteria and lactobacilli living into the lumen [4]. Some properties of FOSC, as their nondigestible and fermentable nature, as well as their sweetening power and low caloric value, make them attractive to be used in pastry, confectionery, and dairy industries [5]. Moreover, both FOSC and inulin are also known as uniquely $\beta(2-1)$ fructans with recognized prebiotic activities [3]. The reported beneficial effects of oral intake of FOSC include the improvement of gastrointestinal metabolism together with short-chain fatty acid production, promotion of mineral absorption and enhancement of bone calcium bioavailability [6], reduction of serum lipids acting as ROS scavenger in gut [7], modulation of immune system [5], and antimicrobial activity against a large broad of pathogenic strains [4]. Although FOSC is recognized to inhibit cellular responses at diverse levels $[8,9]$, little is known about their molecular mechanisms directly involved in cell metabolism or structure [10, 11], as their plausible interaction with cell membranes. In this goal, this work tests the molecular effects of FOSC against biomimetic 
membranes, using reconstituted liposomes and supported bilayer membranes (s-BLM) as target models.

\section{Material and Methods}

2.1. Reagents. L- $\alpha$-Phosphatidylcholine (PC) from fresh egg yolk, fructooligosaccharides from chicory (FOSC), and cholesterol were of the highest obtainable purity and were supplied by Sigma-Aldrich (St. Louis, MO, USA). All other chemicals were of the highest quality as possible and all chemicals were used without further purification. The water used in all experiments was twice distilled.

2.2. Supported Lipid Bilayer Formation. The formation of sBLMs on a Pt electrode has been conducted as reported before [12-14]. Briefly, L- $\alpha$-phosphatidylcholine (PC) was dissolved in chloroform at $20 \mathrm{mg} / \mathrm{mL}$ of final concentration and cholesterol $(\mathrm{CH})$ at $7 \mathrm{mg} / \mathrm{mL}$ (BLM solution). A working Pt electrode ( $0.50 \mathrm{~mm}$ diameter) was first polished with sand paper, followed by alumina slurry on polishing cloth. Then it was sonicated in pure water for $2 \mathrm{~min}$, rinsed, and immersed in a solution of $1.0 \mathrm{~mol} / \mathrm{L} \mathrm{H}_{2} \mathrm{SO}_{4}$. Cyclic voltammetry was performed after Pt electrode activation in $1 \mathrm{~mol} / \mathrm{L} \mathrm{H}_{2} \mathrm{SO}_{4}$. The Pt electrode was immediately taken out, rinsed with pure water again, and sonicated with a highly power supersonic wave generator in water and ethanol bath for $5 \mathrm{~min}$. Following $5 \mu \mathrm{L}$ of BLM forming solution was dropped on the electrode surface. The electrode was then rinsed again with redistilled water to remove chloroform traces and transferred into a $0.1 \mathrm{~mol} / \mathrm{L} \mathrm{KCl}$ solution for $20 \mathrm{~min}$, in which the supported lipid layer was formed spontaneously [15]. All experiments were conducted in triplicate.

2.3. Liposome Preparation. The procedure was done following S. Basu and M. Basu [16]. In short, a chloroform solution containing $\mathrm{PC}$ at $10 \mathrm{mmol} / \mathrm{L}$ was evaporated in test tubes to dry with argon, following evacuation for $60 \mathrm{~min}$ for total remotion of the solvent. Subsequently, the film was hydrated in sodium phosphate buffer $0.1 \mathrm{~mol} / \mathrm{L} \mathrm{pH} 7.4$ or $10 \mathrm{mmol} / \mathrm{L}$ dopamine solution after complete dispersion at room temperature (DA-liposome). Then, the multilamellar vesicles produced were ultrasonicated in water bath for $1 \mathrm{~min}$ and sized by extrusion through Sephadex G-50. This last procedure was conducted whenever $10 \mathrm{mmol} / \mathrm{L}$ dopamine was mixed with PC solution for dopamine incorporation (DA-liposome). The eluted volume was measured by spectrofluorimetry to avoid dopamine freely available in solution. The liposome structure was confirmed by phase contrast and fluorescence microscopy with Rhodamin B with a Nikon Eclipse 80i (Nikon Co., Tokyo, Japan).

2.4. Electrochemical Assays. Cyclic voltammetry (CV) was performed on a potentiostat-galvanostat instrument PG39MCSV (Omni Metra Instr. Cient. Ltda, RJ, Brazil). The apparatus used for electrochemical impedance spectroscopy (EIS) was composed of Autolab with potentiostat/galvanostat working station $128 \mathrm{~N}$ and the Frequency Response Analysis
System Software, FRA (Metrohm Autolab B.V., The Netherlands). Impedance measurements were performed from $100 \mathrm{kHz}$ to $420 \mathrm{mHz}$ with a signal amplitude of $10 \mathrm{mV}$. The experiments were carried out with a three-electrode system composed of an $\mathrm{Ag} / \mathrm{AgCl}$ (KCl-saturated) as reference electrode and a platinum wire $(0.5 \mathrm{~mm}$ diameter $)$ as the counter electrode. The working electrode comprised a $\mathrm{Pt}$ disc of $0.5 \mathrm{~mm}$ diameter melted in a glass tube. EIS runs were performed in the presence of $1 \mathrm{mmol} / \mathrm{L} \mathrm{Fe}(\mathrm{CN})_{6}{ }^{3-/ 4-}$ as a redox probe contained in $0.1 \mathrm{~mol} / \mathrm{L} \mathrm{KCl}$ as support solution and at a system potential of $\mathrm{E}^{0}$ of $235 \mathrm{mV}$. The working electrode was cleaned before use with MaxiClean 1400 (Unique Ind. Com. Ltda, SP, Brazil). The experiments were conducted at room temperature.

2.5. Spectrofluorimetry of Liposomes. The action of FOSC against reconstituted liposomes containing dopamine was also monitored by spectrofluorimetry [17]. The fluorescence measurements were performed with a Cary Eclipse spectrofluorophotometer (Varian, Australia) with a $10 \mathrm{~mm}$ quartz cuvette at an excitation wavelength of $279 \mathrm{~nm}$. The fluorescence emission spectra were recorded in the $300-400 \mathrm{~nm}$ wavelength range with a $5 \mathrm{~nm}$ bandwidth. Spectrofluorimetric runs were carried out after $5 \mathrm{~min}$ of preincubation of liposomes with $5 \mathrm{mmol} / \mathrm{L}$ SDS (sodium dodecyl sulfate) or FOSC (up to $7.5 \mathrm{mg} / \mathrm{mL}$ ).

2.6. Data Analysis. All of the experiments were conducted in triplicate. The data are expressed as the means \pm SE. Statistical analysis was done with the free computing environment $\mathrm{R}(\mathrm{R}$ Core Development Team) [18].

\section{Results and Discussion}

3.1. Characterization of $s-B L M$ and Study of Interaction of Fructans on the Pt Electrode for EIS. Surface-modified electrodes can also be assessed by electrochemical approaches as EIS and CV [19]. In this sense, EIS was carried out aiming to get further information about s-BLM integrity upon the action of tested FOS. The complex impedance can be presented as the sum of the real, $Z_{\mathrm{re}}$, and imaginary, $Z_{\mathrm{im}}$, components that are originated mainly from the resistance and capacitance of the cell, respectively (Nyquist plot [14]). The resulting data can be analyzed by a relatively equivalent Randles circuit consisting of an ideal and nonideal electrical analogs to the real physical and chemical processes, a theoretical abstraction of an interfacial system [20]. Figure 1 illustrates the results of impedance spectroscopy measurements on the bare electrode, whereas Figure 2 presents the results obtained with the electrode coated with s-BLM (a) and after interaction for $10 \mathrm{~min}$ with $5.0 \mathrm{~g} / \mathrm{L}$ of fructooligosaccharides from chicory (b) in $0.1 \mathrm{~mol} / \mathrm{L} \mathrm{KCl}$ solution containing $1 \mathrm{mmol} / \mathrm{L} \mathrm{Fe}(\mathrm{CN})_{6}{ }^{4-/ 3-}$ measured at the formal potential of the system.

For the untreated electrode, a very small circle probed by high frequencies can be visualized near the origin, followed by a Warburg-like mass transfer impedance in the low 


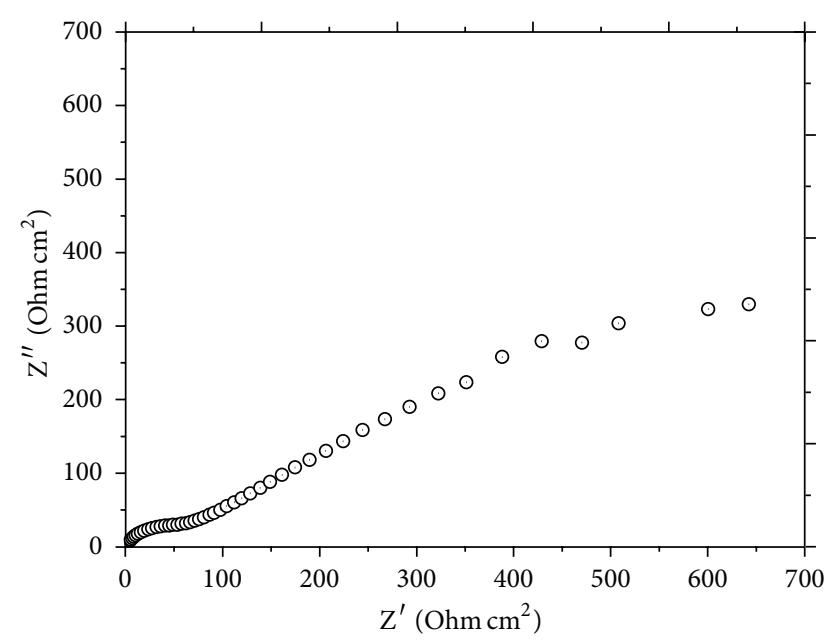

Figure 1: Electrochemical impedance spectroscopy of bare $\mathrm{Pt}$ electrode in $1 \mathrm{mmol} / \mathrm{L} \mathrm{Fe}(\mathrm{CN})_{6}{ }^{4-/ 3-}$ solution containing $0.1 \mathrm{~mol} / \mathrm{L}$ $\mathrm{KCl}$.

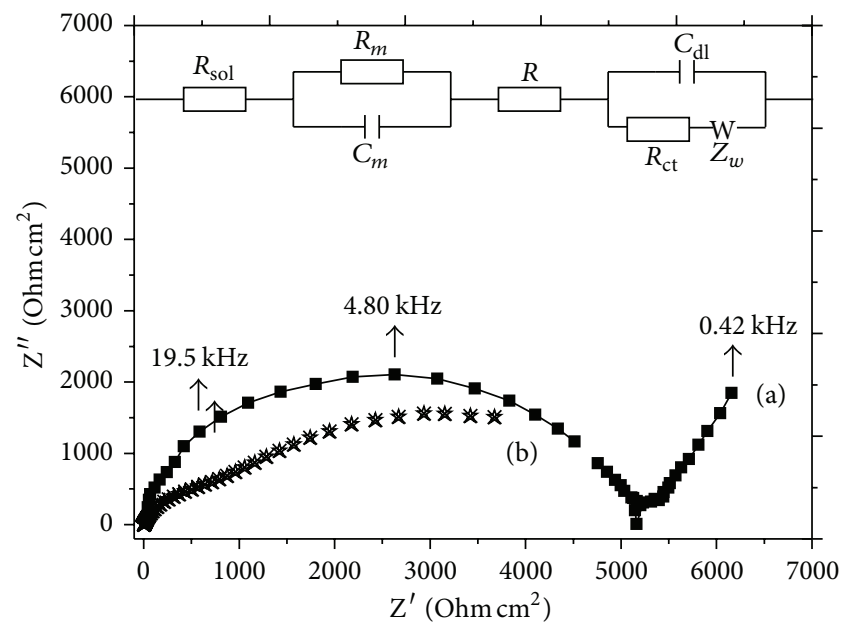

FIgURE 2: Electrochemical impedance spectroscopy of (a) Pt electrode modified with s-BLM and (b) after interaction for $20 \mathrm{~min}$ with $5.0 \mathrm{~g} / \mathrm{L}$ of fructooligosaccharides from chicory in $1 \mathrm{~mol} / \mathrm{L}$ $\mathrm{Fe}(\mathrm{CN})_{6}{ }^{4-/ 3-}$ solution containing $0.1 \mathrm{~mol} / \mathrm{L} \mathrm{KCl}$. Inset: modified Randles equivalent circuit presenting the fitting curve. $R_{\text {sol }}$ denotes the electrolyte resistance, $R_{m}$ denotes the lipid membrane resistance, $C_{m}$ denotes the lipid membrane capacitance, $C_{\mathrm{dl}}$ denotes the double layer capacitance, $R$ is resistance of the monolayer defects, $R_{\mathrm{ct}}$ denotes the charge-transfer resistance, and $Z_{w}$ denotes the Warburg element.

frequency region (Figure 1). This finding suggests a kineticdriven control for the faradaic current produced from voltage excitation [15]. On the other side, a random motion of redox species around the interfacial region seems to have appeared, as observed by the unitary slope of Nyquist plot (Figure 1) in the low frequency region of spectra [21].

Figure 2(b) shows the results of impedance spectroscopy of s-BLM after interacting with $5.0 \mathrm{~g} / \mathrm{L}$ of fructooligosaccharides from chicory for $10 \mathrm{~min}$, in equimolar $1 \mathrm{mmol} / \mathrm{L}$ $\mathrm{Fe}(\mathrm{CN})_{6}{ }^{4-/ 3-}$ solution with $0.1 \mathrm{~mol} / \mathrm{L} \mathrm{KCl}$ as supporting electrolyte. A smaller diameter with a decrease in the chargetransfer resistance can be devised in Figure 2(b) as compared to Figure 2(a), suggesting an effectiveness of s-BLM on prevention of the redox probe from accessing the electrode $[20,22]$. Furthermore this result suggested a Warburg-like mass transfer impedance occurring in the low frequency portion, which indicated that s-BLM after interaction was deficient to eliminate electron transfer between $\mathrm{Fe}(\mathrm{CN})_{6}{ }^{4-/ 3-}$ and the covered electrode [23]. This result suggests a s-BLM as having a fractal surface with defects permeating through membrane to the electrode after fructans binding.

A major difference in the spectra however can be observed whenever the s-BLM was treated with FOSC (Figure 2(b)), with the presence of one semicircle at higher frequency and another one in the average frequency of the spectra. This finding is expected when a resistive film is present on electrode surface and with higher impedance values [21]. The two capacitive arcs can be hardly separated, as the nearness of two time constants for the capacitors. At higher frequencies the data suggest the presence of another membrane behaviour, whereas at medium frequencies, an interfacial contact with the electrode solution due to the sBLM pores. A prevention of the electron-ion probe transfer can also be attested from the observed semicircle in the modified electrode. A relatively equivalent circuit model consisting of ideal and nonideal electrical analogs of the physical-chemical process has been chosen from several electrical models to the impedance data to extract the circuit components [12-14, 24, 25]. Hence, the modified Randles equivalent circuit, similar to that presented by Huang et al. [12], has fitted better the measured data (Figure 2, inset). Through simulation it was confirmed that the s-BLM is formed by the resistance of the solution $\left(R_{\text {sol }}\right)$, two capacitors in series $\left(R_{m}, C_{m}, R_{\mathrm{ct}}\right.$, and $\left.C_{\mathrm{dl}}\right)$, and Warburg impedance $\left(Z_{w}\right)$. In this model, $R_{m}$ is the membrane resistance, $C_{m}$ is the membrane capacitance per unit area, $R_{c t}$ is the chargetransfer resistance, and $C_{\mathrm{dl}}$ is the double layer capacitance. The values for equivalent electrical circuit were $R_{\text {sol }}$ of 0.128 $\mathrm{m} \Omega \cdot \mathrm{cm}^{2}$ (0.0\% error), $C_{m}$ of $0.16 \mu \mathrm{F} / \mathrm{cm}^{2}$ ( $0.0 \%$ error), $R_{m}$ of $3.46 \mathrm{k} \Omega \cdot \mathrm{cm}^{2}\left(0.0 \%\right.$ error), $R_{\mathrm{ct}}$ of $1.39 \mathrm{k} \Omega \cdot \mathrm{cm}^{2}$ ( $2.8 \%$ error), and $C_{\mathrm{dl}}$ of $0.11 \mu \mathrm{F} / \mathrm{cm}^{2}$ (3.3\% error). These values are in accordance with those reported before [12, 13, 24-26].

From these findings, a Warburg impedance highlights the presence of molecular pores in the s-BLM structure [24]. Furthermore, defects in s-BLM related to monolayers can be assigned to the resistance $R$ values merging the capacitors. From the $C_{m}$ value found in this work, close to the ones published before $[24,27]$, the thickness $d$ of the biomimetic membrane can be estimated according to Du et al. as follows [25]:

$$
C_{m}=\frac{\varepsilon_{0} \cdot \kappa}{d}
$$

where $\varepsilon_{0}$ is the dielectric permittivity of free space $\left(\varepsilon_{0}=8.85 \times\right.$ $\left.10^{-14} \mathrm{~F} \cdot \mathrm{cm}^{-1}\right)$ and $\kappa$ is the dielectric permittivity of the lipid $(\kappa=2.05,[13])$. From (1) a value of $11.3 \mathrm{~nm}$ for the thickness of the lipid membranes, close to range of $4-10 \mathrm{~nm}$, was found and observed for phosphatidylcholine bilayers [27, 28]. 
3.2. Characterization of $s-B L M$ on the Electrode Surface by Cyclic Voltammetry. Cyclic voltammetry with $\mathrm{Fe}(\mathrm{CN})_{6}^{4-/ 3-}$ as ion probe $[29,30]$ was carried out to examine the sBLM integrity upon challenge with FOSC. Figure 3 shows the voltammograms of (a) the bare Pt electrode and (b) the Pt electrode coated with s-BLM in $1.0 \mathrm{mmol} / \mathrm{L} \mathrm{K}_{3}\left[\mathrm{Fe}(\mathrm{CN})_{6}\right] /$ $\mathrm{K}_{4}\left[\mathrm{Fe}(\mathrm{CN})_{6}\right](1: 1)$ solution containing $0.1 \mathrm{~mol} / \mathrm{L} \mathrm{KCl}$. The s-BLM is considered a highly effective barrier for electron transfer between the bulk and the electrode surface. In this sense, a pair of well-defined reversible waves can be visualized for bare Pt [31], with decreasing current signal as s-BLM is formed on the electrode surface up to the disappearance of both redox peaks (Figure 3(b)) [27, 28, 32].

3.3. Preincubation Effects of Fructans on s-BLM. Pt electrodes coated with s-BLM immersed into $5.0 \mathrm{~g} / \mathrm{L}$ FOSC solutions for $0,5,10,15,30$, and $50 \mathrm{~min}$ were transferred into a $0.1 \mathrm{~mol} / \mathrm{L} \mathrm{KCl}$ solution containing $1.0 \mathrm{mmol} / \mathrm{L} \mathrm{K}_{3}\left[\mathrm{Fe}(\mathrm{CN})_{6}\right] /$ $\mathrm{K}_{4}\left[\mathrm{Fe}(\mathrm{CN})_{6}\right](1: 1)$. The resulted voltammograms are displayed in Figure 4. As expected, no voltammetric peaks were found in the absence of FOSC (Figure 4(a)). However, when the fructans were preincubated with s-BLM a faradaic current due to the probe transport to the electrode surface appeared for different times (Figure 4, (b)-(f)). These results evoke membrane defects arising around 5 min after preincubation with the fructans and can be explained by adsorption of FOSC molecules [12] and/or rearrangement of s-BLM structure [13].

Aiming to test the hypothesis of the reappearance of faradaic current as due to pore formation in Pt-s-BLM, we have used the treatment of Amatore et al. [33] for partially blocked electrodes. According to this theoretical approach, the half-wave potential of a limiting current $\left(i_{\lim }\right)$ of a bare electrode can be represented by the standard potential of a redox couple in a pure diffusion-controlled electron transfer. The relationship between the fractional coverage of electrode $(\theta)$ and $i_{\text {lim }}$ can then be given by [28]

$$
\theta=1-\frac{\left(0.6 \cdot i_{\lim } \cdot r\right)}{F A C D}
$$

where $r$ is the average radii of active pinhole sites, $F$ is the Faraday constant, $A$ is the surface area, $C$ is the concentration of oxidant or reductant $\left(\mathrm{mol} \cdot \mathrm{dm}^{3}\right)$, and $D$ is the diffusion coefficient. This approach resulted in pore radii for s-BLM FOSC-induced $33 \AA[34]$.

3.4. Concentration Effects of FOSC on s-BLM. After interaction of the fructans with s-BLM, increasing redox peaks due to $\mathrm{Fe}(\mathrm{CN})_{6}{ }^{4-/ 3-}$ could be attained in $0.1 \mathrm{~mol} / \mathrm{L} \mathrm{KCl}$ solution, as depicted in voltammograms at Figure 5. The peak separation decreased and peak current increased with increasing fructans concentration. Nevertheless, below $2.5 \mathrm{~g} / \mathrm{L}$ of FOS, no faradaic current for the marker ion was observed (data not shown).

To evaluate the electron transfer rate in the presence of the fructans, the Tafel approach [32] was applied to the rising part of anodic branch of the voltammograms. The electron transfer rate $K s$ changed linearly with FOSC concentration $\left(2.2 \times 10^{-4} \cdot \mathrm{s}^{-1}\right.$ at $2.5 \mathrm{~g} / \mathrm{L}$, to $4.6 \times 10^{-4} \cdot \mathrm{s}^{-1}$ at $12.5 \mathrm{~g} / \mathrm{L}$;

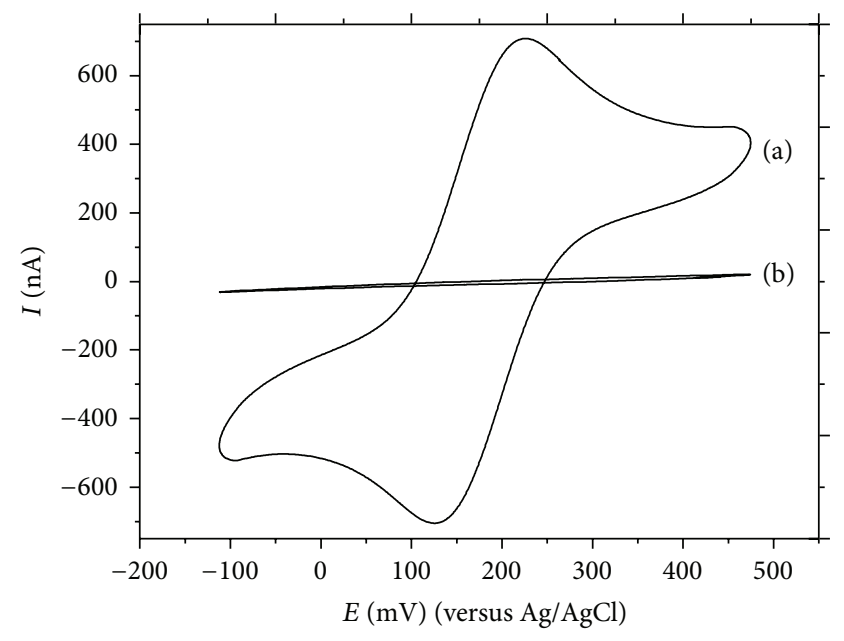

FIGURE 3: Cyclic voltammetry of charge transfer of ferricyanide ions on the electrode surface at bare Pt electrode (a) and Pt electrode modified with s-BLM (b) in $1.0 \mathrm{mmol} / \mathrm{L} \mathrm{K}_{3}\left[\mathrm{Fe}(\mathrm{CN})_{6}\right] / \mathrm{K}_{4}\left[\mathrm{Fe}(\mathrm{CN})_{6}\right]$ (1:1) mixture containing $0.1 \mathrm{~mol} / \mathrm{L} \mathrm{KCl}$. Scan rate $50 \mathrm{mV} \cdot \mathrm{s}^{-1}$.

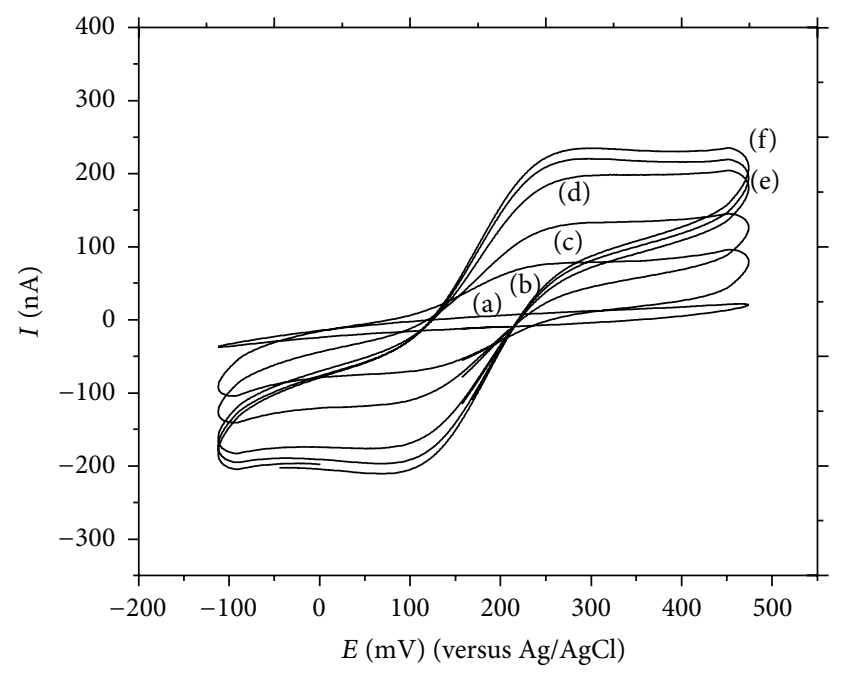

FIgURE 4: Electrochemical data for FOSC action on s-BLM as a function of preincubation times. Cyclic voltammetric response of $1.0 \mathrm{mmol} / \mathrm{L} \mathrm{K}_{3}\left[\mathrm{Fe}(\mathrm{CN})_{6}\right] / \mathrm{K}_{4}\left[\mathrm{Fe}(\mathrm{CN})_{6}\right](1: 1)$ solution containing $0.1 \mathrm{~mol} / \mathrm{L} \mathrm{KCl}$, at Pt electrode s-BLM after interaction with $5.0 \mathrm{~g} \cdot \mathrm{L}$ of FOSC for different times: (a) $0 \mathrm{~min}$, (b) $5 \mathrm{~min}$, (c) $10 \mathrm{~min}$, (d) $15 \mathrm{~min}$, (e) $30 \mathrm{~min}$, and (f) $50 \mathrm{~min}$. Scan rate $50 \mathrm{mV} \cdot \mathrm{s}^{-1}$.

$R^{2}=0.988$ ), revealing $47.7 \pm 3.5 \%$ of the anodic peak current obtained for FOS, as compared to the unmodified electrode [13]. These increased values found for $K s$ suggest an increased surface area for charge transfer on the electrode surface with fructans binding [23], possibly inducing some active sites to $\mathrm{Fe}(\mathrm{CN})_{6}{ }^{4-/ 3-}$ ions through the pores of s-BLM [23]. Although there are other mechanisms proposed in the literature to explain membrane defects from electrochemical responses of s-BLMs with active molecules, the data of EIS and CV presented in this work indicate a most probable formation of pores fructan-induced on the surface of s-BLM, leading to decreased membrane resistivity to the probing molecules [14, 


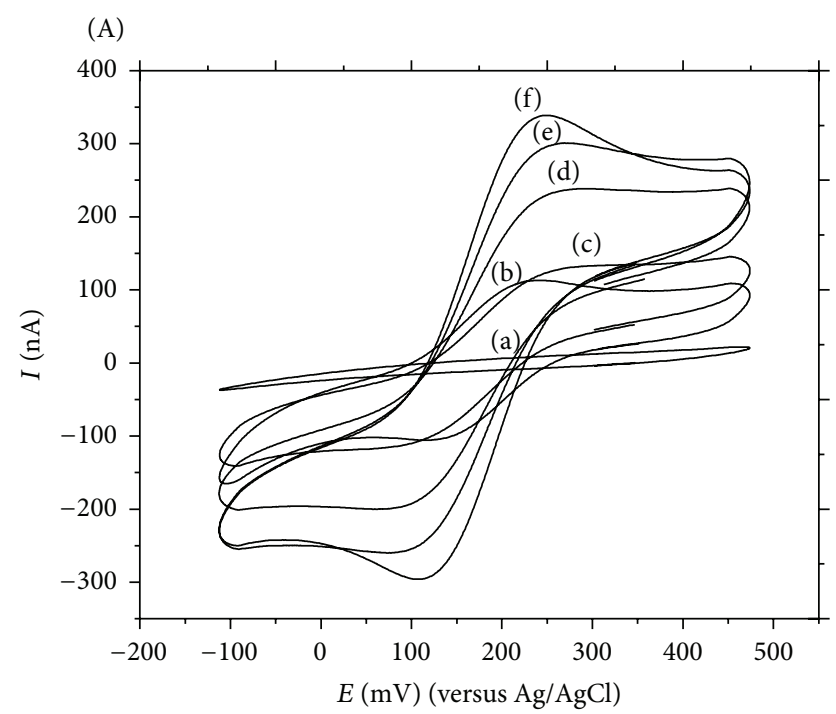

FIgURE 5: Electrochemical data for FOSC action on supported lipid bilayer membrane as a function of fructan concentration. Cyclic voltammetric response of $1.0 \mathrm{mmol} / \mathrm{L} \mathrm{K} \mathrm{K}_{3}\left[\mathrm{Fe}(\mathrm{CN})_{6}\right] / \mathrm{K}_{4}\left[\mathrm{Fe}(\mathrm{CN})_{6}\right]$ $(1: 1)$ solution containing $0.1 \mathrm{~mol} / \mathrm{L} \mathrm{KCl}$, at Pt-s-BLM after interaction with different concentrations of FOSC for $20 \mathrm{~min}$ : (a) 0.0, (b) 2.5 , (c) 5.0, (d) 7.5 , (e) 10.0, and (f) $12.5 \mathrm{~g} / \mathrm{L}$. Scan rate $50 \mathrm{mV} \cdot \mathrm{s}^{-1}$.

$23,25,28]$. These results can also discard stabilization on sBLM induced by adsorption [25], as there was no evidence for current peak decrease simultaneously to the increase in $\Delta \mathrm{Ep}$ values [25]. Moreover, the similar ion permeability for the redox $\mathrm{Fe}(\mathrm{CN})_{6}{ }^{4-/ 3-}$ couple through s-BLM (unitary ipa/ipc ratio, Figure 5) also discards the possibility of an ionophorelike action and channel formation for the tested fructans [35, $36]$. Hence, a surfactant-like effect $[12,37,38]$ can be proposed to explain the mechanism of interaction between FOSC and s-BLM. This mechanism is similar to those reported for some active peptides [39] and classical surfactants [37, 39]. This binding model is also supported by the hydrogen bonding found between the polyhydroxy groups of carbohydrates and the phosphate head groups of phospholipids, as studied from IR spectroscopy [40, 41]. In this sense, it is believed that the polyhydroxylated sugar replaces water and keeps the lateral spacing between lipid polar head groups in the dry state, thereby minimizing van der Waals interactions of the hydrocarbon chains [41].

3.5. Action of FOSC on Prepared Liposome. Aiming to test the action of FOSC in another membrane model, liposomes containing dopamine (DA-liposomes) as a fluorescent probe were prepared and monitored against FOSC by fluorimetry and microscopy. The increase in fluorescence intensity, which is related to the dopamine release in liposome suspensions (DA-liposome) treated with SDS as control or FOS, was measured following the relation below [42]:

$$
L \%=100 \%-\left(\frac{I_{i}-I_{b}}{I_{t}-I_{b t}}\right)
$$

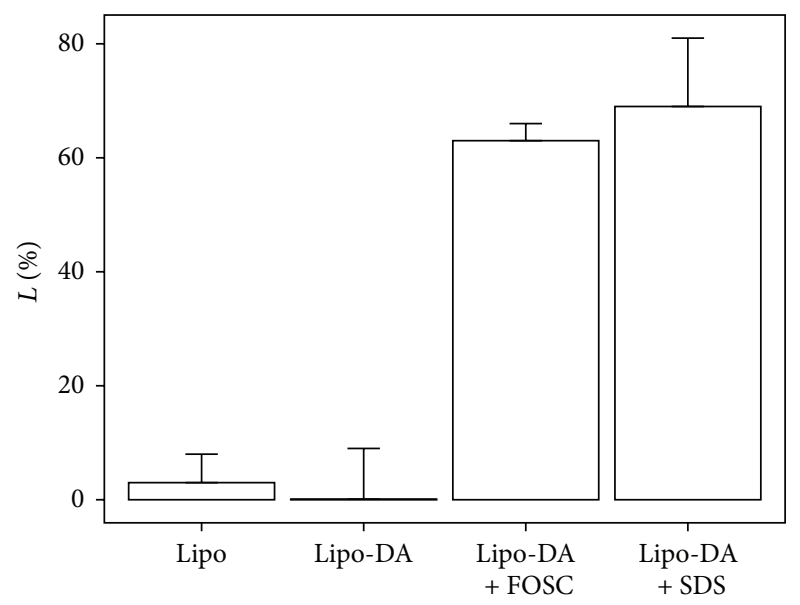

FIGURE 6: Relative changes in fluorescence intensity ( $L \%)$ of multilamellar liposomes and reconstituted DA-liposomes (Lipo-DA) challenged with SDS $(5 \mathrm{mmol} / \mathrm{L})$ and FOSC at $7.5 \mathrm{mg} / \mathrm{mL}$.

where $L \%$ is the percentage of the signal increase from dopamine release, $I_{i}$ is the fluorescence of liposome dispersions, $I_{b}$ is the background fluorescence, $I_{t}$ is the fluorescence after addition of SDS or FOSC, and $I_{b t}$ is the background fluorescence after addition of these compounds. Figure 6 presents the results obtained after preincubation of DAliposomes with $5 \mathrm{mmol} / \mathrm{L}$ SDS or $7.5 \mathrm{mg} / \mathrm{mL}$ FOSC. The prebiotic oligosaccharide was able to increase the fluorescence intensity in solution up to $62 \pm 2 \%$ from the basal level, close to the value presented for the surfactant SDS. This finding suggests a FOS-induced membrane rupture occurring with the liposomes, releasing dopamine molecules freely in the solution.

The direct action of FOSC on s-BLM structure can also be corroborated with both fluorescence and phase contrast photomicrography obtained for the treatment of the reconstituted liposomes, as presented in Figure 7. Rhodamin B stained regular liposomes (arrowheads) before FOS treatment under fluorescence (a) and phase contrast (b) microscopy. After FOSC treatment, the liposomes become irregularly shaped (arrowheads) and disrupted (arrows) under fluorescent Rhodamin B (c) and phase contrast microscopy $(\mathrm{d})$.

\section{Conclusion}

We have studied the interaction of fructooligosaccharides from chicory with two biomimetic models of membrane, supported bilayer membrane, and reconstituted liposomes, by means of electrochemical, spectroscopy, and microscopy techniques. The overall results suggest that the mechanism of interaction seems to involve some hydrogen bonding between carbohydrate and the phosphate head group of the phospholipids, leading to the appearance of progressive pinholes on the biomimetic membranes, up to a complete disruption of the membrane structures. This mechanism of action directly on a membrane model could 


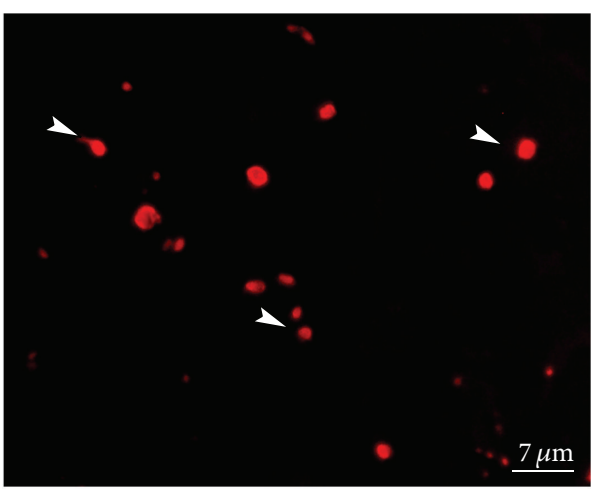

(a)

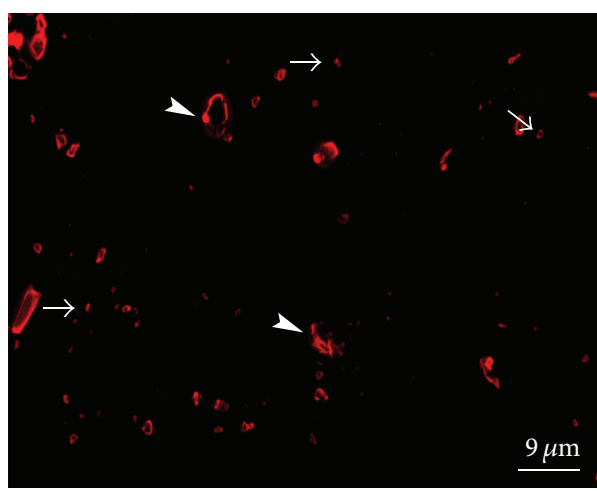

(c)

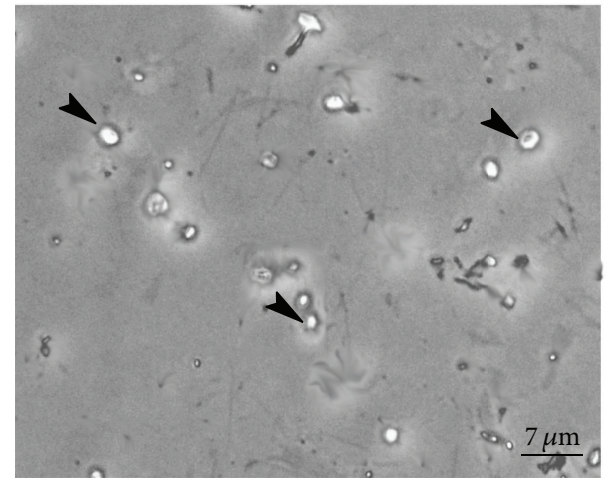

(b)

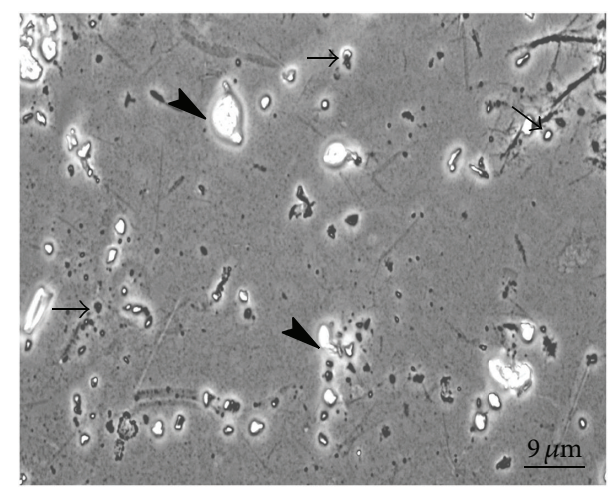

(d)

FIGURE 7: Photomicrography of reconstituted liposomes before ((a) and (b)) challenged with FOSC ((c) and (d)). Liposomes were identified by Rhodamin B labeled probe ((a) and (c)) and phase contrast ((b) and (d)). The arrows are explained in the text.

provide some thoughts to the biological activity of prebiotics.

\section{Conflict of Interests}

The authors declare that there is no conflict of interests regarding the publication of this paper.

\section{Acknowledgment}

The authors acknowledge the Minas Gerais State Research Foundation-FAPEMIG, for the financial support of this work (Grant no. CBB APQ 01920/11).

\section{References}

[1] G. R. Gibson and M. B. Roberfroid, "Dietary modulation of the human colonic microbiota: introducing the concept of prebiotics," Journal of Nutrition, vol. 125, no. 6, pp. 1401-1412, 1995.

[2] M. B. Roberfroid, "Chicory fructooligosaccharides and the gastrointestinal tract," Nutrition, vol. 16, no. 7-8, pp. 677-679, 2000 .
[3] E. Biedrzycka and M. Bielecka, "Prebiotic effectiveness of fructans of different degrees of polymerization," Trends in Food Science \& Technology, vol. 15, no. 3-4, pp. 170-175, 2004.

[4] T. Fukasawa, A. Kamei, Y. Watanabe, J. Koga, and K. Abe, "Short-chain fructooligosaccharide regulates hepatic peroxisome proliferator-activated receptor $\alpha$ and farnesoid $\mathrm{X}$ receptor target gene expression in Rats," Journal of Agricultural and Food Chemistry, vol. 58, no. 11, pp. 7007-7012, 2010.

[5] F. R. J. Bornet, F. Brouns, Y. Tashiro, and V. Duvillier, "Nutritional aspects of short-chain fructooligosaccharides: natural occurrence, chemistry, physiology and health implications," Digestive and Liver Disease, vol. 34, supplement 2, pp. S111-S120, 2002.

[6] A. Nzeusseu, D. Dienst, V. Haufroid, G. Depresseux, J.P. Devogelaer, and D.-H. Manicourt, "Inulin and fructooligosaccharides differ in their ability to enhance the density of cancellous and cortical bone in the axial and peripheral skeleton of growing rats," Bone, vol. 38, no. 3, pp. 394-399, 2006.

[7] W. van den Ende, D. Peshev, and L. de Gara, "Disease prevention by natural antioxidants and prebiotics acting as ROS scavengers in the gastrointestinal tract," Trends in Food Science and Technology, vol. 22, no. 12, pp. 689-697, 2011.

[8] N. Matsukawa, M. Matsumoto, A. Shinoki, M. Hagio, R. Inoue, and H. Hara, "Nondigestible saccharides suppress the bacterial degradation of quercetin aglycone in the large intestine and enhance the bioavailability of quercetin glucoside in rats," 
Journal of Agricultural and Food Chemistry, vol. 57, no. 20, pp. 9462-9468, 2009.

[9] J. M. Laparra and Y. Sanz, "Interactions of gut microbiota with functional food components and nutraceuticals," Pharmacological Research, vol. 61, no. 3, pp. 219-225, 2010.

[10] T. Suzuki and H. Hara, "Various nondigestible saccharides open a paracellular calcium transport pathway with the induction of intracellular calcium signaling in human intestinal Caco-2 cells," The Journal of Nutrition, vol. 134, no. 8, pp. 1935-1941, 2004.

[11] T. Fukasawa, K. Murashima, T. Nemoto et al., "Identification of marker genes for lipid-lowering effect of a short-chain fructooligosaccharide by DNA microarray analysis," Journal of Dietary Supplements, vol. 6, no. 3, pp. 254-262, 2009.

[12] W. Huang, Z. Zhang, X. Han et al., "Concentration-dependent behavior of nisin interaction with supported bilayer lipid membrane," Biophysical Chemistry, vol. 99, no. 3, pp. 271-279, 2002.

[13] Y. Ma, J. Wang, F. Hui, and S. Zang, “The reassembled behavior of bilayer lipid membranes supported by Pt electrode," Journal of Membrane Science, vol. 286, no. 1-2, pp. 174-179, 2006.

[14] X. Lu, T. Liao, L. Ding et al., "Interaction of quercetin with supported bilayer lipid membranes on glassy carbon electrode," International Journal of Electrochemical Science, vol. 3, no. 7, pp. 797-805, 2008.

[15] D. Jiang, P. Diao, R. Tong, D. Gu, and B. Zhong, " $\mathrm{Ca}^{2+}$ induced $\mathrm{Fe}(\mathrm{CN})_{6}{ }^{3-/ 4-}$ electron transfer at Pt supported BLM electrode," Bioelectrochemistry and Bioenergetics, vol. 44, no. 2, pp. 285288, 1998.

[16] S. Basu and M. Basu, Liposome Methods and Protocols, Methods in Molecular Biology, Humana Press, New York, NY, USA, 2002.

[17] H. Y. Wang, Y. Sun, and B. Tang, "Study on fluorescence property of dopamine and determination of dopamine by fluorimetry," Talanta, vol. 57, no. 5, pp. 899-907, 2002.

[18] R Development Core Team, R: A Language and Environment for Statistical Computing, R Foundation for Statisti cal Computing, Vienna, Austria, 2012.

[19] J. J. Harris and M. L. Bruening, "Electrochemical and in situ ellipsometric investigation of the permeability and stability of layered polyelectrolyte films," Langmuir, vol. 16, no. 4, pp. 20062013, 2000.

[20] P. Diao, D. Jiang, X. Cui, D. Gu, R. Tong, and B. Zhong, "Cyclic voltammetry and a.c. impedance studies of $\mathrm{Ca}^{2+}$-induced ion channels on Pt-BLM," Bioelectrochemistry and Bioenergetics, vol. 45, no. 2, pp. 173-179, 1998.

[21] D. Pan, J. Chen, W. Tao, L. Nie, and S. Yao, "Phosphopolyoxomolybdate absorbed on lipid membranes/carbon nanotube electrode," Journal of Electroanalytical Chemistry, vol. 579, no. 1, pp. 77-82, 2005.

[22] N. Wilke and A. M. Baruzzi, "Comparative analysis of the charge transfer processes of the $\mathrm{Ru}\left(\mathrm{NH}_{3}\right)_{6}^{3+} / \mathrm{Ru}\left(\mathrm{NH}_{3}\right)_{6}^{2+}$ and $\mathrm{Fe}(\mathrm{CN})_{6}^{3-} / \mathrm{Fe}(\mathrm{CN})_{6}^{4-}$ redox couples on glassy carbon electrodes modified by different lipid layers," Journal of Electroanalytical Chemistry, vol. 537, no. 1-2, pp. 67-76, 2002.

[23] J. Wang, L. Wang, S. Liu, X. Han, W. Huang, and E. Wang, "Interaction of $\mathrm{K}_{7} \mathrm{Fe}^{3+} \mathrm{P}_{2} \mathrm{~W}_{17} \mathrm{O}_{62} \mathrm{H}_{2}$ with supported bilayer lipid membranes on platinum electrode," Biophysical Chemistry, vol. 106, no. 1, pp. 31-38, 2003.

[24] X. Liu, W. Huang, and E. Wang, "An electrochemical study on the interaction of surfactin with a supported bilayer lipid membrane on a glassy carbon electrode," Journal of Electroanalytical Chemistry, vol. 577, no. 2, pp. 349-354, 2005.

[25] L. Du, X. Liu, W. Huang, and E. Wang, "A study on the interaction between ibuprofen and bilayer lipid membrane," Electrochimica Acta, vol. 51, no. 26, pp. 5754-5760, 2006.
[26] J. Wang, B. Zeng, C. Fang, and X. Zhou, "Influence of surfactants on the electron-transfer reaction at self-assembled thiol monolayers modifying a gold electrode," Journal of Electroanalytical Chemistry, vol. 484, no. 1, pp. 88-92, 2000.

[27] J.-S. Ye, A. Ottova, H. T. Tien, and F.-S. Sheu, "Nanostructured platinum-lipid bilayer composite as biosensor," Bioelectrochemistry, vol. 59, no. 1-2, pp. 65-72, 2003.

[28] G. Favero, A. D’Annibale, L. Campanella, R. Santucci, and T. Ferri, "Membrane supported bilayer lipid membranes array: preparation, stability and ion-channel insertion," Analytica Chimica Acta, vol. 460, no. 1, pp. 23-34, 2002.

[29] K. Asaka, H. Ti Tien, and A. Ottova, "Voltammetric study of charge transfer across supported bilayer lipid membranes (sBLMs)," Journal of Biochemical and Biophysical Methods, vol. 40, no. 1-2, pp. 27-37, 1999.

[30] V. Kochev and M. Karabaliev, "Wetting films of lipids in the development of sensitive interfaces. An electrochemical approach," Advances in Colloid and Interface Science, vol. 107, no. 1, pp. 9-26, 2004.

[31] C. G. Zoski, Handbook of Electrochemistry, vol. 5, Elsevier, New York, NY, USA, 2007.

[32] H. Haas, G. Lamura, and A. Gliozzi, "Improvement of the quality of self assembled bilayer lipid membranes by using a negative potential," Bioelectrochemistry, vol. 54, no. 1, pp. 1-10, 2001.

[33] C. Amatore, J. M. Savéant, and D. Tessier, "Charge transfer at partially blocked surfaces. A model for the case of microscopic active and inactive sites," Journal of Electroanalytical Chemistry, vol. 147, no. 1-2, pp. 39-51, 1983.

[34] N. Yang, Q. Wan, and X. Wang, "Voltammetry of Vitamin $\mathrm{B}_{12}$ on a thin self-assembled monolayer modified electrode," Electrochimica Acta, vol. 50, no. 11, pp. 2175-2180, 2005.

[35] H. Sato, H. Hakamada, Y. Yamazaki, M. Uto, M. Sugawara, and Y. Umezawa, "Ionophore incorporated bilayer lipid membranes that selectively respond to metal ions and induce membrane permeability changes," Biosensors and Bioelectronics, vol. 13, no. 9, pp. 1035-1046, 1998.

[36] W. Huang, Z. Zhang, X. Han et al., "Ion channel behavior of Amphotericin B in sterol-free and cholesterol- or ergosterolcontaining supported phosphatidylcholine bilayer model membranes investigated by electrochemistry and spectroscopy," Biophysical Journal, vol. 83, no. 6, pp. 3245-3255, 2002.

[37] S. Schreier, S. V. P. Malheiros, and E. de Paula, "Surface active drugs: self-association and interaction with membranes and surfactants. Physicochemical and biological aspects," Biochimica et Biophysica Acta: Biomembranes, vol. 1508, no. 1-2, pp. 210234, 2000.

[38] X. Liu, H. Bai, W. Huang, L. Du, X. Yang, and E. Wang, "Concentration and time dependant behavior of chlorpromazine interaction with supported bilayer lipid membrane," Electrochimica Acta, vol. 51, no. 12, pp. 2512-2517, 2006.

[39] Z. Oren and Y. Shai, "Mode of action of linear amphipathic $\alpha$ helical antimicrobial peptides," Biopolymers, vol. 47, no. 6, pp. 451-463, 1998.

[40] L. M. Crowe, J. H. Crowe, and D. Chapman, "Interaction of carbohydrates with dry dipalmitoylphosphatidylcholine," Archives of Biochemistry and Biophysics, vol. 236, no. 1, pp. 289296, 1985.

[41] J. Grdadolnik and D. Hadži, "FT infrared and Raman investigation of saccharide-phosphatidylcholine interactions using novel structure probes," Spectrochimica Acta A: Molecular and Biomolecular Spectroscopy, vol. 54, no. 12, pp. 1989-2000, 1998. 
[42] L. Paasonen, T. Laaksonen, C. Johans, M. Yliperttula, K. Kontturi, and A. Urtti, "Gold nanoparticles enable selective lightinduced contents release from liposomes," Journal of Controlled Release, vol. 122, no. 1, pp. 86-93, 2007. 

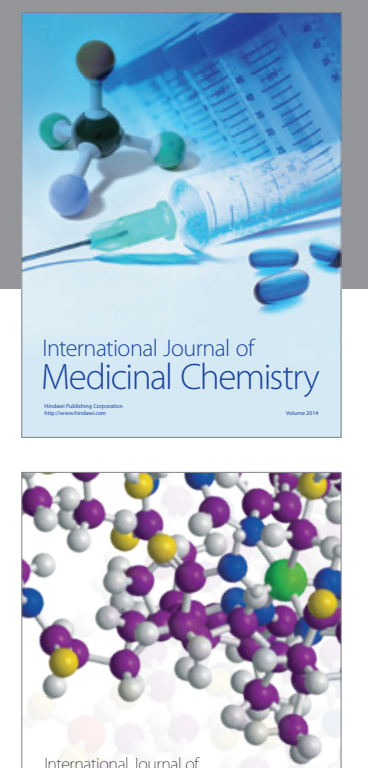

\section{Carbohydrate} Chemistry

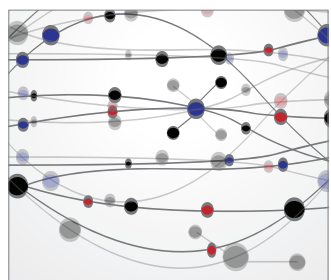

The Scientific World Journal
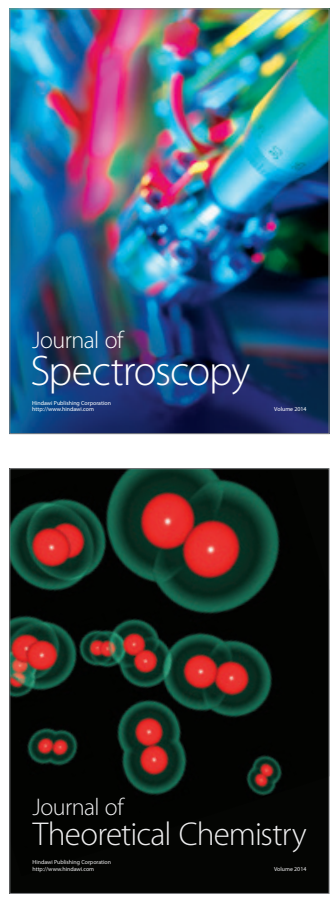
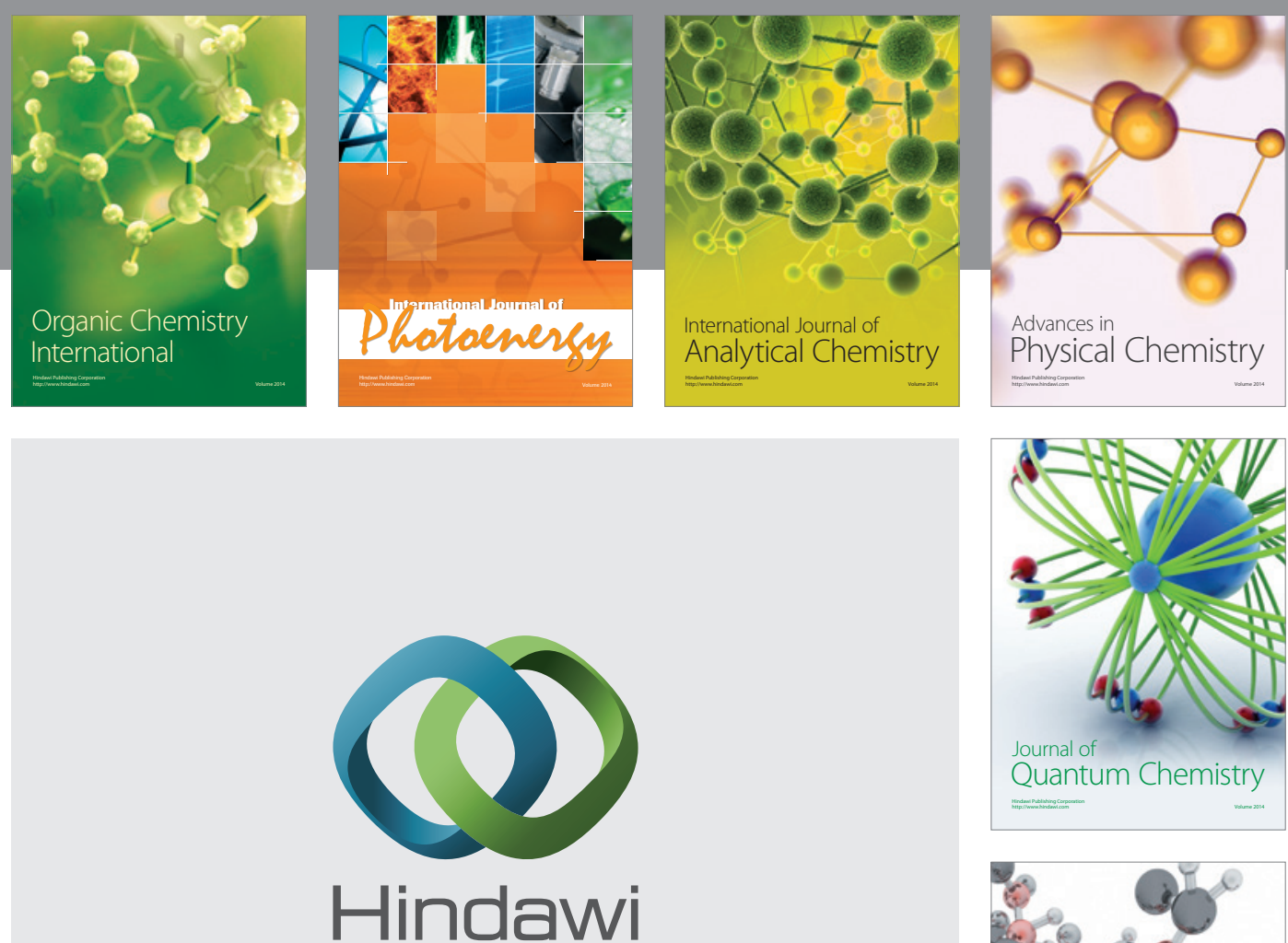

Submit your manuscripts at

http://www.hindawi.com

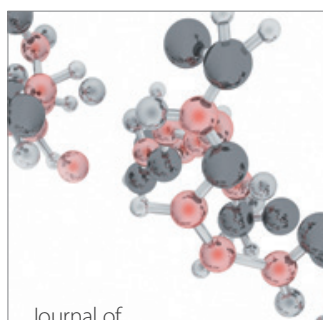

Analytical Methods

in Chemistry

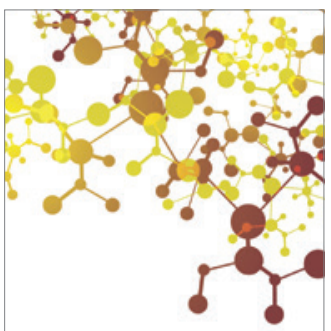

Journal of

Applied Chemistry

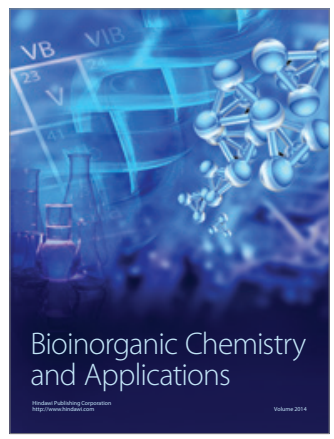

Inorganic Chemistry
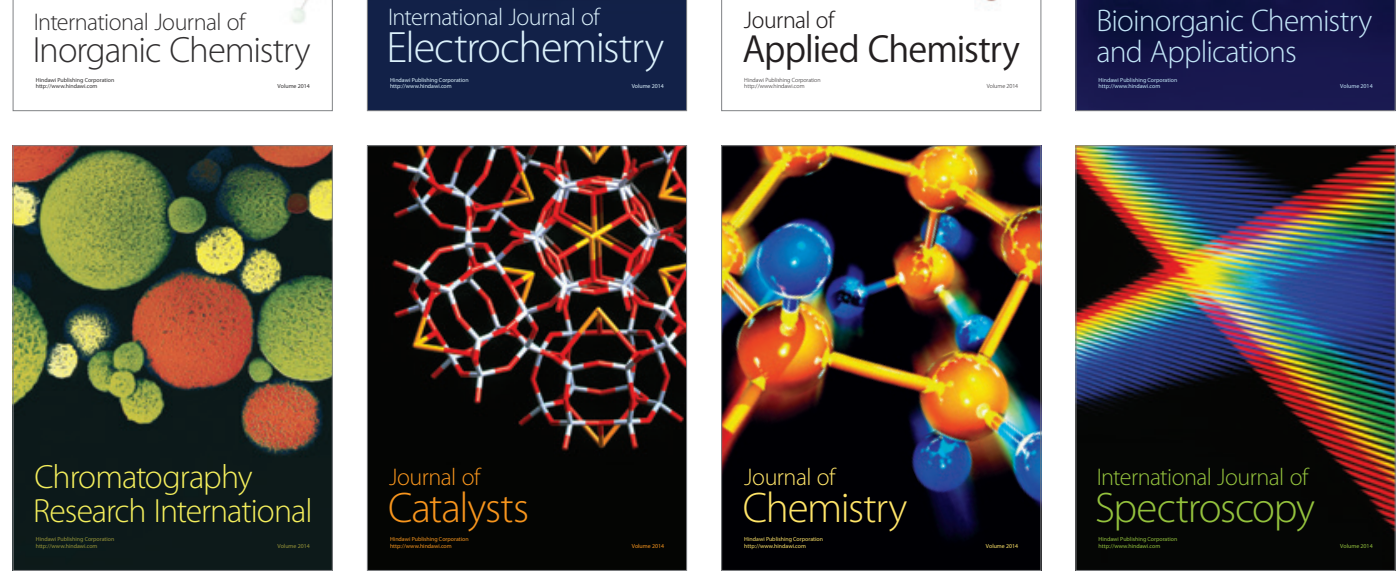